\title{
Mission Benefits Analysis of Logistics Reduction Technologies
}

\author{
Michael K. Ewert, James L. Broyan \\ NASA Johnson Space Center, Houston, TX
}

\begin{abstract}
Future space exploration missions will need to use less logistical supplies if humans are to live for longer periods away from our home planet. Anything that can be done to reduce initial mass and volume of supplies or reuse or recycle items that have been launched will be very valuable. Reuse and recycling also reduce the trash burden and associated nuisances, such as smell, but require good systems engineering and operations integration to reap the greatest benefits. A systems analysis was conducted to quantify the mass and volume savings of four different technologies currently under development by NASA's Advanced Exploration Systems (AES) Logistics Reduction and Repurposing project. Advanced clothing systems lead to savings by direct mass reduction and increased wear duration. Reuse of logistical items, such as packaging, for a second purpose allows fewer items to be launched. A device known as a heat melt compactor drastically reduces the volume of trash, recovers water and produces a stable tile that can be used instead of launching additional radiation protection. The fourth technology, called trash-to-supply-gas, can benefit a mission by supplying fuel such as methane to the propulsion system. This systems engineering work will help improve logistics planning and overall mission architectures by determining the most effective use, and reuse, of all resources.
\end{abstract}

